\title{
Analysis of Risk Factors for Adjacent Segment Degeneration Occurring More than 5 Years after Fusion with Pedicle Screw Fixation for Degenerative Lumbar Spine
}

\author{
Jaewan Soh ${ }^{1}$, Jae Chul Lee ${ }^{2}$, Byung Joon Shin ${ }^{2}$ \\ ${ }^{1}$ Department of Orthropaedic Surgery, Soonchunhyang University Hospital, Soonchunhyang University College of Medicine, Cheonan, Korea \\ ${ }^{2}$ Department of Orthopaedic Surgery and Spine Center, Soonchunhyang University College of Medicine, Seoul, Korea
}

\begin{abstract}
Study Design: A retrospective study.
Purpose: We investigated the risk factors in adjacent segment degeneration (ASD) after more than 5 years of follow-up of lumbar spinal fusion.

Overview of Literature: There are many concerns regarding ASD followed by lumbar spinal fusion. However, there is a great deal of dispute about the risk factors.

Methods: A total of 55 patients who were followed up for more than 5 years after lumbar fusion were observed. Gender, age, residence, fusion method, number of fusion segments and radiological measurements were analyzed. In the radiological measurement, disc height, lumbar lordotic angle (LLA), fusion segment lordotic angle and fusion segment lordotic angle per level (FSLA per level) were estimated. In preoperative MRI, Pfirrmann's classification was used. The clinical result was evaluated by the criteria of Kim and Kim. Statistical univariate analysis was performed with the chi-square test by using SPSS ver. 12.0. Multivariate logistic regression analysis was conducted with SAS ver. 9.

Results: There were 21 patients with adjacent segment degeneration. Further, there was little relationship between ASD and gender, age, residence, fusion method, number of fusion segments, degree of preoperative adjacent disc degeneration in MRI, or preoperative and postoperative LLA. However, the frequency of ASD was significantly low in cases where FSLA per level was $>15^{\circ}(p=0.009)$. There was no significant relationship between ASD and the clinical result.

Conclusions: In patients followed up for more than 5 years after lumbar spinal fusion, the most important factor in the prevention of ASD was the restoration of FSLA per level to $>15^{\circ}$.
\end{abstract}

Keywords: Lumbar; Adjacent segment degeneration; Fusion; Pedicle screw fixation

\section{Introduction}

When a structural deformation or nerve compression is so severe that simple decompression alone does not produce satisfactory outcomes for degenerative lumbar disease, extensive decompression and lumbar vertebral

Received Jun 20, 2013; Revised Aug 16, 2013; Accepted Aug 20, 2013

Corresponding author: Byung Joon Shin

Department of Orthopaedic Surgery, Soonchunhyang University College of Medicine,

59 Daesagwan-ro, Yongsan-gu, Seoul 140-743, Korea

Tel: +82-2-709-9250, Fax: +82-2-794-9414, E-mail: schsbj@schmc.ac.kr 
fusion to maintain stability are widely-conducted surgical treatments.

Although some fusion methods and fixation systems have been developed to achieve successful fusion in spinal surgery, a long-term follow-up after a strong fusion has revealed degenerative changes at the adjacent segments due to the loss of mobility of the fusion site and the mechanical load caused thereby $[1,2]$. Degenerative changes at the adjacent segments include segmental instability, spinal stenosis, intervertebral disc lesion, retro-spondylolisthesis and fracture [3-5]. These poor outcomes are known to follow the accelerated degenerative changes at the adjacent segments after fusion $[2,6,7]$. As these complications are observed during a long-term follow-up, a cautious application of the fusion itself as well as new alternatives have been suggested. Therefore, measures to reduce and treat degenerative changes after fusion are discussed, along with the increased interest in causative factors related to the prevention and treatment reported by many studies. Nevertheless, these are still controversial.

On the basis of previous studies, in order to determine its causative factors, we statistically analyzed the correlation between possible factors and the degenerative change in adjacent segments among patients with radiographic changes during middle- or long-term follow-up of over 5 years after fusion with pedicle screw. In addition, we investigated the correlation between a radiological degenerative change at the adjacent segments and the actual clinical symptoms in order to show whether the radiological change was an index of the actual abnormality. We define that the degenerative change in the adjacent segment with a radiographic change is 'adjacent segment degeneration', and the adjacent segment degeneration with clinical symptom is 'adjacent segment disease'.

\section{Materials and Methods}

\section{Materials}

The subjects of this study were 55 patients who had undergone pedicle screw fixation and spine fusion of three or fewer segments due to degenerative lumbar disease. The patients had been followed up for over 5 years. Their mean age at operation was 50.2 years (range, $34-67$ years) and they consisted of 18 males and 37 females. Their mean follow-up period was 8 years and 6 months (range,
60-190 months). All of the surgery was performed by one orthopedic surgeon. The fusion methods were posterolateral fusion and posterior lumbar interbody fusion in 24 and 31 cases, respectively (Table 1).

\section{Methods}

The 55 subjects were retrospectively investigated with their medical records and radiological findings.

Criteria of degenerative change at adjacent segments: radiological degenerative change at the adjacent segments was considered to exist when anterior or posterior displacement of $>3 \mathrm{~mm}$ was found on the X-ray of the sagittal plane of the closest upper segment and the closest lower segment at the last follow-up, when the height of the intervertebral disc relative to that of the upper interbody had declined by $20 \%$ and when a segmental motion instability of more than $15^{\circ}$ was observed on the X-ray of the sagittal plane with flexion and extension.

1) Patient-related factors

Gender, age and lifestyle by residential area were analyzed as patient-related factors, which could have some influence. Age was examined by dividing the patients into two groups: $\geq 50$ years and $<50$ years of age (mean, 50 years). The effect of differences in lifestyle was examined by classifying residential areas into urban and rural categories.

\section{2) Preoperative lumbar factors}

Magnetic resonance imaging (MRI) was used to investigate whether there had been a degree of preoperative adjacent disc degeneration. Patients recording grade $\geq \mathrm{III}$ in the five-grade classification of Pfirrmann et al. [8] based on MRI were considered to have a degenerative change. In addition, the preoperative lumbar lordotic angle was measured by Cobb's angle made by the upper endplate of the first lumbar vertebra and the upper endplate of the sacrum. It was classified, with its mean value of $32^{\circ}$ as a standard, into $\geq 32^{\circ}$ and $<32^{\circ}$; moreover, its correlation with a degenerative change at the adjacent segments was assessed.

\section{3) Surgery-related factors}

As factors related to surgical treatment, fusion method (posterolateral fusion or posterior lumbar interbody fusion) and the number of fusion segments (one, two and three segments) were analyzed. 




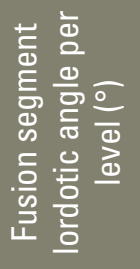



흥

豆 $\frac{0}{\frac{1}{c}}$

홍릉

๗

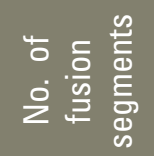

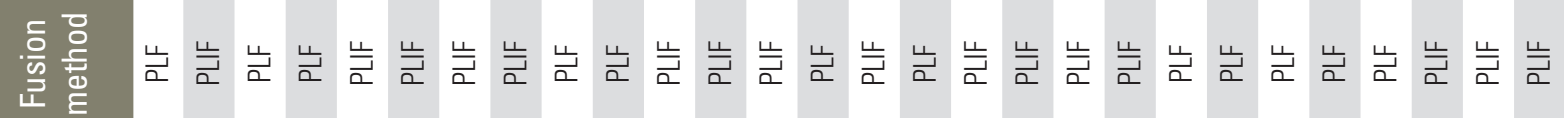

$\stackrel{\circ}{\circ}$

离

旁

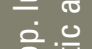

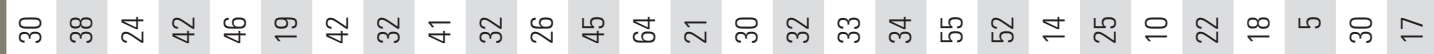

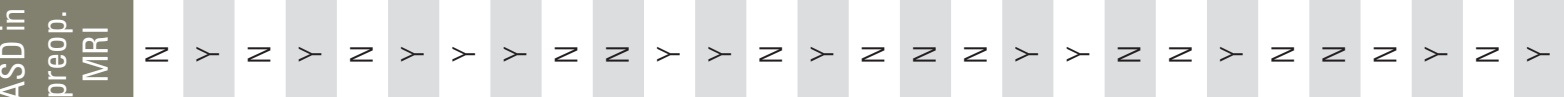

离

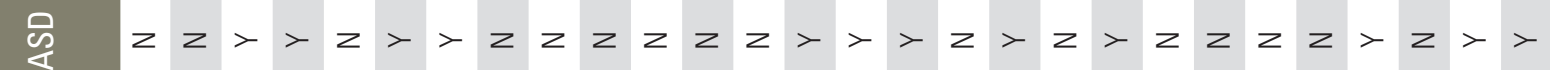

产



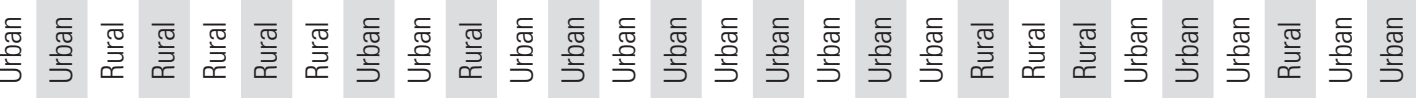

产

ฯ

눌흐을

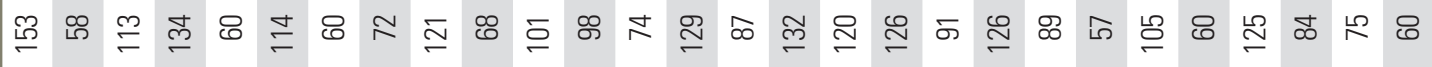

인 한

号

范

㐫

론








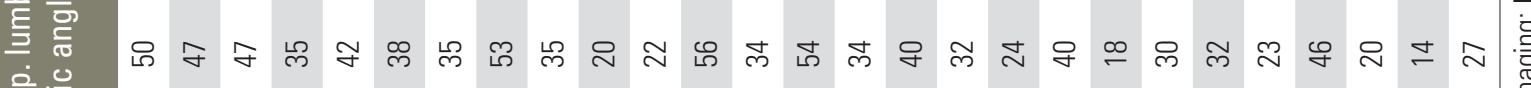
흥은 高





(2)

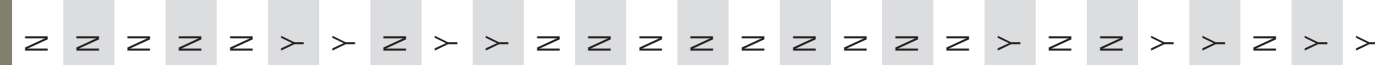

焉

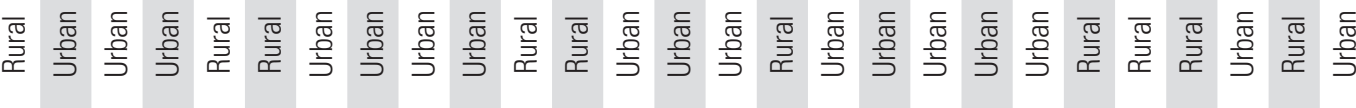


4) Postoperative radiological change-related factors Measures from the radiological images taken just after surgery were evaluated as surgical outcomes. First, the postoperative lumbar lordotic angle was classified, with its mean value of $40^{\circ}$ as a standard, into $\geq 40^{\circ}$ and $<40^{\circ}$, and the meaning of each group was analyzed. Next, the fusion segment lordotic angle per level was calculated by dividing the lordotic angle of the fusion site or a Cobb's angle between the upper endplate of the fusion segment and the lower endplate of the fusion segment by the number of fused segments. It was also divided, with its mean of $15^{\circ}$, into $\geq 15^{\circ}$ and $<15^{\circ}$, and its correlation with the degenerative change of adjacent segments was assessed.

5) Correlation between radiological degenerative change in adjacent segment and clinical symptoms

The relationship between degenerative change in the adjacent segments and clinical outcome was assessed. The clinical outcomes were divided into satisfactory (excellent, good) and unsatisfactory (fair, poor) on the basis of the assessment base of the criteria of Kim and Kim [9].

\section{6) Statistical analysis}

To verify the significance of each factor, a univariate analysis was performed with the chi-square test by using SPSS ver. 12.0 (SPSS Inc., Chicago, IL, USA). Multivariate logistic regression analysis including all factors was also performed with SAS ver. 9 (SAS Institute, Cary, NC, USA), and the odds ratio of the significant factors was calculated. The significance level was $p<0.05$.

\section{Results}

\section{Radiological degenerative change at adjacent segments}

Degenerative change at the adjacent segments was observed in a total of 21 cases. The change occurred at the upper segments (14 of retrolisthesis, seven of decreased height of the intervertebral disc, seven of segmental motion instability, and one of spondylolisthesis) in 18 cases, at the lower segments (one of retrolisthesis, two of decreased height of the intervertebral disc and one of spondylolisthesis) in four cases, and there was one case that showed the change at both the upper and lower segments.

\section{Analysis on causative factors}

1) Patient-related factors

According to the analysis of patient-related factors, the subjects included 18 males and 37 females, and the postoperative degenerative change was found in seven males and 14 females; hence, there was no significant difference by gender $(p=0.940)$. The age of the subjects was $\geq 50$ years and $<50$ years in 34 and 21 cases, respectively. The degenerative change did not show any significant difference by age as it was found in 14 out of the 34 cases with the age of $\geq 50$ years and in seven out of the 21 aged $<50$ years $(p=0.561)$. The relationship between degenerative change and differences in residential area as lifestyle was examined. The change was observed in 12 of 35 residents of urban areas and nine of 20 resident in rural areas; there was no statistically significant correlation $(p=0.431)$ (Table 2).

\section{2) Preoperative lumbar factors}

When the influence of the degree of preoperative adjacent disc degeneration was investigated by MRI, the degenerative change at the adjacent segments was found at the last follow-up in 11 out of 29 cases with and ten out of 26 without preoperative degenerative change; the difference was not statistically significant ( $p=0.968$ ). In addition, the degenerative change was observed in eight and 13 among 27 and 28 cases with the preoperative lumbar lordotic angle of $\geq 32^{\circ}$ and $<32^{\circ}$, respectively; hence, there was no significant difference $(p=0.200)$ (Table 2$)$.

\section{3) Surgery-related factors}

When the difference by the fusion method was investigated, the degenerative change was found in 11 and 10 out of 24 and 31 cases treated with posterolateral fusion and posterior lumbar interbody fusion, respectively, and the difference was not statistically significant $(p=0.304)$. As for the number of fusion segments, one-segment fusion and two- and three-segment fusions were performed in 26 and 29 cases, respectively, and the degenerative change was observed in eight and 13, respectively. There was also no significant difference $(p=0.284)$ (Table 2$)$.

4) Postoperative radiological change-related factors When the influence of the postoperative lumbar lordotic angle on the degenerative change at the adjacent segments was investigated, the change was found in ten and 
Table 2. Univariate analysis of risk factors for adjacent segment degeration

\begin{tabular}{|c|c|c|c|}
\hline Risk factors & $\begin{array}{c}\text { No. of } \\
\text { patients }\end{array}$ & ASD & $p$-value \\
\hline \multicolumn{4}{|l|}{ Patient-related factors } \\
\hline Gender & & & 0.940 \\
\hline Male & 18 & 7 & \\
\hline Female & 37 & 14 & \\
\hline Age (yr) & & & 0.561 \\
\hline$<50$ & 21 & 7 & \\
\hline$\geq 50$ & 34 & 14 & \\
\hline Residence & & & 0.431 \\
\hline Urban & 35 & 12 & \\
\hline Rural & 20 & 9 & \\
\hline \multicolumn{4}{|l|}{ Preoperative lumbar factors } \\
\hline Preoperative ADD on MRI & & & 0.986 \\
\hline Yes & 29 & 11 & \\
\hline No & 26 & 10 & \\
\hline Preoperative LLA & & & 0.200 \\
\hline$<32^{\circ}$ & 28 & 13 & \\
\hline$\geq 32^{\circ}$ & 27 & 8 & \\
\hline \multicolumn{4}{|l|}{ Surgery-related factors } \\
\hline Fusion method & & & 0.304 \\
\hline PLF & 24 & 11 & \\
\hline PLIF & 31 & 10 & \\
\hline Nor of fusion segments & & & 0.284 \\
\hline Single & 26 & 8 & \\
\hline 2 or 3 & 29 & 13 & \\
\hline \multicolumn{4}{|c|}{ Postoperative radiological-related factors } \\
\hline Postoperative LLA & & & 0.551 \\
\hline$<40^{\circ}$ & 26 & 11 & \\
\hline$\geq 40^{\circ}$ & 29 & 10 & \\
\hline FSLA per level & & & 0.009 \\
\hline$<15^{\circ}$ & 27 & 15 & \\
\hline$\geq 15^{\circ}$ & 28 & 6 & \\
\hline \multicolumn{4}{|c|}{ Correlation between ASD and clinical symptom } \\
\hline Clinical result & & & 0.405 \\
\hline Satisfactory & 44 & 18 & \\
\hline Unsatisfactory & 11 & 3 & \\
\hline
\end{tabular}

$A S D$, adjacent segment degeneration; $A D D$, adjacent disc degeneration; MRI, magnetic resonance imaging; LLA, lumbar lordotic angle; PLF, posterolateral fusion; PLIF, posterior lumbar interbody fusion; FSLA, fusion segment lordotic angle.
11 cases out of 29 and 26 with the angle $\geq 40^{\circ}$ and $<40^{\circ}$, and the difference was not significant $(p=0.551)$. In addition, the fusion segment lordotic angle per level recorded $\geq 15^{\circ}$ and $<15^{\circ}$ in 28 and 27 cases, respectively, and the degenerative change was shown in six and 15 cases, respectively. Thus, their difference was statistically significant $(p=0.009)$ (Table 2).

5) Correlation between radiological degenerative change of adjacent segments and clinical symptoms

For the correlation between the degenerative change of adjacent segments and clinical outcomes, the change was shown in 18 out of 44 cases with satisfactory clinical outcomes and three out of 11 with unsatisfactory outcomes. As there was no significant difference, the radiological change did not imply unsatisfactory clinical outcomes $(p=0.405)$ (Table 2).

Among the 21 cases with change at the adjacent segments, three needed a revision surgery $(14.3 \%, 5.5 \%$ out of the total subjects); two of these were surgically treated for spinal stenosis at the upper adjacent segments, and the other one was treated for segmental instability.

When the multivariate logistic regression analysis on risk factors was conducted-with independent variables as gender, age, residential area, fusion method, degree of preoperative adjacent disc degeneration on MRI, the number of fusion segments, and the lumbar lordotic angle and the fusion segment lordotic angle per level at the fusion site after the surgery-the fusion segment lordotic angle per level of $<15^{\circ}$ increased the risk of degenerative change at the adjacent segments 4.666 times (range, 1.015-21.439 times) (Table 3).

\section{Discussion}

Decompression and lumbar vertebral fusion have been widely conducted as surgical treatment for lumbar degenerative change. Spinal fusion provoked a conflict between benefits secured just after the surgery and future problems. The complications of lumbar vertebral fusion, such as intervertebral disc degeneration at adjacent segments, instability, fatigue and fracture, were observed during middle- and long-term follow-up [3-5]. Although many researchers have pointed out the degenerative lesions at the adjacent segments occurring frequently after fusion as major causes of these late complications [2,6,7], their causes, frequencies and risk factors are still controversial. 
Table 3. Multivariate logistic regression analysis including all risk factors

\begin{tabular}{|c|c|c|c|c|}
\hline \multirow{2}{*}{ Risk factors } & \multirow{2}{*}{$p$-value } & \multirow{2}{*}{ Odds ratio } & \multicolumn{2}{|c|}{$95 \% \mathrm{Cl}$} \\
\hline & & & Upper & Lower \\
\hline Gender & 0.9712 & 1.026 & 0.257 & 4.088 \\
\hline Age & 0.2131 & 3.284 & 0.508 & 21.241 \\
\hline Residence & 0.3185 & 0.499 & 0.128 & 1.954 \\
\hline Fusion method & 0.8535 & 0.821 & 0.101 & 6.680 \\
\hline Preoperative ADD on MRI & 0.6413 & 0.707 & 0.164 & 3.039 \\
\hline Number of fusion segments & 0.9026 & 0.878 & 0.109 & 7.097 \\
\hline Preoperative LLA $\left(32^{\circ}\right)$ & 0.2962 & 2.162 & 0.509 & 9.182 \\
\hline Postoperative $\operatorname{LLA}\left(40^{\circ}\right)$ & 0.8032 & 0.827 & 0.185 & 3.693 \\
\hline FSLA per level $\left(15^{\circ}\right)$ & 0.0478 & 4.666 & 1.015 & 21.439 \\
\hline
\end{tabular}

$\mathrm{Cl}$, confidence interval; $\mathrm{ADD}$, adjacent disc degeneration; MRI, magnetic resonance imaging; LLA, lumbar lordotic angle; FSLA, fusion segment lordotic angle.

It is the predominant view that the degenerative lesion at the adjacent segments can be part of normal aging, and that the reduced mobility and the mechanical load following lumbar fusion accelerates the degeneration [1$3,10,11]$. This biomechanical change at the adjacent segments is affected by the range of fused segments and the sagittal angle, and stronger fixation of fused segments is known to be associated with a larger effect as more stress is put on the adjacent segments $[12,13]$. Cunningham et al. [14] reported that the pressure of the adjacent intervertebral disc became larger by $45 \%$ in their cadaveric study, and Lee and Langrana [15] found that the load at the adjacent segments was raised in their biomechanical study on lumbosacral fusion. For the influence of gender, Kumar et al. [16] and Ha et al. [17] showed no significant difference in the rate of the degenerative change by gender, while Etebar and Cahill [18] insisted that the rate of the change at the adjacent segments was higher in females after menopause. This study did not reveal any significant difference by gender.

Many researchers believe that older age leads to more change at the adjacent segments [10,18-21]. As reasons for that, Aota et al. [20] pointed out that it was more difficult for the spine to adapt to postoperative biomechanical change in the elderly, whereas Etebar and Cahill [18] reported that osteoporosis negatively affected the existing degenerative procedure. However, we found no significant correlation between age and the degenerative change at the adjacent segments. As for the effect of lifestyle, Gillet [22] and Cho et al. [23] reported that differences in lifestyle could influence the adjacent segments, and Ahn et al. [24] reported that manual workers and residents in rural areas had around 47 times higher risk compared with those in urban areas. However, no significant correlation with residential area was observed in this study.

When the cases with preoperative instability or intervertebral disc degeneration at the adjacent segments were reviewed, Aota et al. [20] reported that instability deteriorated after the surgery in all cases with preoperative anterior displacement of $\geq 3 \mathrm{~mm}$. Ha et al. [21] showed that preoperatively, more severe degenerative change in the adjacent joints was associated with more radiological change in the joints, and no degenerative change was observed for more than 5 years of follow-up in cases without preoperative degenerative change in the joints. However, this study did not show any direct correlation between preoperative adjacent disc degeneration on MRI and postoperative degenerative change at the adjacent segments.

Schlegel et al. [13] revealed that the change at the adjacent segments occurred early in the fusion when a device was used for fixation, and Rahm and Hall [2] insisted that posterior intervertebral body fusion increased the load over adjacent segments because the remaining mobility after bone fusion was excluded along with stronger initial fixation. However, Kim et al. [25] and Ha et al. [21] found no significant difference in the frequency of the degenerative change by the fixation system or fusion method. This study also showed that the correlation between the fusion method and degenerative change was not significant. Moreover, there was no significant difference in the degenerative change by the number of fusion segments. 
Although Aota et al. [20] and Etebar and Cahill [18] insisted that the changes at the adjacent segments became larger due to more stress on the segments for multi-level fusion, Kettler et al. [26] and Ha et al. [17] reported that there was no correlation between the number of fusion segments and the change. This study also indicated no significant correlation between them.

For the change at the adjacent segments by the sagittal angle, reduced lordotic angle has been reported to promote the degenerative change early by leading to a concentrated load of segmental motion at the adjacent segments $[27,28]$. Herkowitz and Kurz [29], Cho et al. [23] and Ahn et al. [24] stated that it was critical to maintain the lumbar lordotic angle during follow-up after fusion, and decreased lordotic angle eventually stimulated the degenerative change at the adjacent segments. For the segmental sagittal angle, Ahn et al. [19] found that the decrease in the fusion segment lordotic angle by $10^{\circ}$ was associated with 3.2 times the increase in the degenerative change. In this study, the degenerative change was observed more frequently in the cases where the fusion segment lordotic angle per level was $<15^{\circ}$ after the surgery.

The incidence rate of the degenerative change at the adjacent segments after lumbar vertebral fusion has been reported variously as between $19.4 \%$ and $40 \%$ $[3,20,21,25]$. When it was investigated whether the degenerative change provoked clinical symptoms, Booth et al. [6] reported that a radiological degenerative change was found in many cases in $>5$ years after lumbar vertebral fusion; however, there were almost no cases with this symptom; other previous studies also revealed no correlation between radiological change and clinical symptoms $[2,18,23,30]$. This study found that unsatisfactory outcomes were observed in only 11 among 21 cases with the degenerative change at the adjacent segments, and that the correlation between radiological change and surgical outcomes was not statistically significant. However, it was reported that if clinical symptoms were observed again along with the degenerative change at the adjacent segments, surgical treatments were necessary in $8 \%$ to $16.8 \%$ of cases $[14,20,25]$. This study also revealed that three (14.3\%) out of the 21 cases needed surgical treatment.

\section{Conclusions}

During the long-term follow-up after pedicle screw fixation and fusion, gender, age, residential area, fusion method, the number of fusion segments, and the degree of preoperative adjacent disc degeneration on MRI showed no significant relationship with the postoperative degenerative change at the adjacent segments; however, the correlation between the fusion segment lordotic angle per level and the postoperative degenerative change was significant. Therefore, efforts to restore the fusion segment lordotic angle per level to $>15^{\circ}$ are most important and are considered to be able to reduce the degenerative change at the adjacent segments.

\section{Conflict of Interest}

No potential conflict of interest relevant to this article was reported.

\section{Acknowledgments}

This work was supported by the Soonchunhyang University Research Fund.

\section{References}

1. Boden SD, McCowin PR, Davis DO, Dina TS, Mark AS, Wiesel S. Abnormal magnetic-resonance scans of the cervical spine in asymptomatic subjects. A prospective investigation. J Bone Joint Surg Am 1990;72:1178-84.

2. Rahm MD, Hall BB. Adjacent-segment degeneration after lumbar fusion with instrumentation: a retrospective study. J Spinal Disord 1996;9:392-400.

3. Brunet JA, Wiley JJ. Acquired spondylolysis after spinal fusion. J Bone Joint Surg Br 1984;66:720-4.

4. Leong JC, Chun SY, Grange WJ, Fang D. Long-term results of lumbar intervertebral disc prolapse. Spine (Phila Pa 1976) 1983;8:793-9.

5. Whitecloud TS 3rd, Davis JM, Olive PM. Operative treatment of the degenerated segment adjacent to a lumbar fusion. Spine (Phila Pa 1976) 1994;19:531-6.

6. Booth KC, Bridwell KH, Eisenberg BA, Baldus CR, Lenke LG. Minimum 5-year results of degenerative spondylolisthesis treated with decompression and instrumented posterior fusion. Spine (Phila Pa 1976) 1999;24:1721-7.

7. Frymoyer JW, Matteri RE, Hanley EN, Kuhlmann D, Howe J. Failed lumbar disc surgery requiring second operation. A long-term follow-up study. Spine (Phila 
Pa 1976) 1978;3:7-11.

8. Pfirrmann CW, Metzdorf A, Zanetti M, Hodler J, Boos N. Magnetic resonance classification of lumbar intervertebral disc degeneration. Spine (Phila $\mathrm{Pa}$ 1976) 2001;26:1873-8.

9. Kim NH, Kim DJ. Anterior interbody fusion for spondylolisthesis. Orthopedics 1991;14:1069-76.

10. Quinnell RC, Stockdale HR. Some experimental observations of the influence of a single lumbar floating fusion on the remaining lumbar spine. Spine (Phila Pa 1976) 1981;6:263-7.

11. Yang SW, Langrana NA, Lee CK. Biomechanics of lumbosacral spinal fusion in combined compressiontorsion loads. Spine (Phila Pa 1976) 1986;11:937-41.

12. Okuda S, Iwasaki M, Miyauchi A, Aono H, Morita M, Yamamoto T. Risk factors for adjacent segment degeneration after PLIF. Spine (Phila Pa 1976) 2004;29:1535-40.

13. Schlegel JD, Smith JA, Schleusener RL. Lumbar motion segment pathology adjacent to thoracolumbar, lumbar, and lumbosacral fusions. Spine (Phila Pa 1976) 1996;21:970-81.

14. Cunningham BW, Kotani Y, McNulty PS, Cappuccino A, McAfee PC. The effect of spinal destabilization and instrumentation on lumbar intradiscal pressure: an in vitro biomechanical analysis. Spine (Phila $\mathrm{Pa}$ 1976) 1997;22:2655-63.

15. Lee CK, Langrana NA. Lumbosacral spinal fusion. A biomechanical study. Spine (Phila Pa 1976) 1984;9:574-81.

16. Kumar MN, Baklanov A, Chopin D. Correlation between sagittal plane changes and adjacent segment degeneration following lumbar spine fusion. Eur Spine J 2001;10:314-9.

17. Ha Ky, Kim YH, Kang KS. Surgery for adjacent segment changes after lumbosacral fusion. J Korean Soc Spine Surg 2002;9:332-40.

18. Etebar S, Cahill DW. Risk factors for adjacentsegment failure following lumbar fixation with rigid instrumentation for degenerative instability. J Neurosurg 1999;90:163-9.

19. Ahn DK, Lee S, Jeong KW, Choi DJ, Cha SK, Cho $\mathrm{KH}$. Degenerative change of adjacent segments according to the fusion method after L4-5 segmental fusion: comparative study of posterolateral fusion and posterior lumbar interbody fusion. J Korean Orthop Assoc 2006;41:281-7.

20. Aota Y, Kumano K, Hirabayashi S. Postfusion instability at the adjacent segments after rigid pedicle screw fixation for degenerative lumbar spinal disorders. J Spinal Disord 1995;8:464-73.

21. Ha KY, Kim KW, Park SJ, Lee YH. Changes of the adjacent-unfused mobile segment after instrumental lumbar fusion: more than 5-years follow-up. J Korean Soc Spine Surg 1998;5:205-14.

22. Gillet P. The fate of the adjacent motion segments after lumbar fusion. J Spinal Disord Tech 2003;16:33845.

23. Cho JL, Park YS, Han JH, Lee CH, Roh WI. The changes of adjacent segments after spinal fusion: follow-up more than three years after spinal fusion. J Korean Soc Spine Surg 1998;5:239-46.

24. Ahn DK, Lee S, Jeong KW, Park JS, Cha SK, Park HS. adjacent segment failure after lumbar spine fusion: controlled study for risk factors. J Korean Orthop Assoc 2005;40:203-8.

25. Kim HT, Kang DW, Yoo CH, Jeoung JH, Chang SA. Late changes at the adjacent segments to lumbar fusions. J Korean Soc Spine Surg 1996;3:1-10.

26. Kettler A, Wilke HJ, Haid C, Claes L. Effects of specimen length on the monosegmental motion behavior of the lumbar spine. Spine (Phila Pa 1976) 2000;25:543-50.

27. Dekutoski MB, Schendel MJ, Ogilvie JW, Olsewski JM, Wallace LJ, Lewis JL. Comparison of in vivo and in vitro adjacent segment motion after lumbar fusion. Spine (Phila Pa 1976) 1994;19:1745-51.

28. Grouw AV, Nadel CI, Weierman RJ, Lowell HA. Long term follow-up of patients with idiopathic scoliosis treated surgically: a preliminary subjective study. Clin Orthop Relat Res 1976;(117):197-201.

29. Herkowitz HN, Kurz LT. Degenerative lumbar spondylolisthesis with spinal stenosis. A prospective study comparing decompression with decompression and intertransverse process arthrodesis. J Bone Joint Surg Am 1991;73:802-8.

30. Ghiselli G, Wang JC, Bhatia NN, Hsu WK, Dawson EG. Adjacent segment degeneration in the lumbar spine. J Bone Joint Surg Am 2004;86:1497-503. 